\title{
SELECTIONOF COLD CHAIN LOGISTICS SERVICE PROVIDERS IN PHARMACEUTICAL INDUSTRY WITH REFERENCE TO INDIA
}

\author{
Saravanan. $S^{1}$ and Anubama. $B^{2}$ \\ ${ }^{1}$ Head of the Department, Department of Management Studies, Anna University (BIT \\ Campus), Tamil Nadu, India. \\ ${ }^{2}$ Student, Department of Management Studies, Anna University (BIT Campus), Tamil \\ Nadu, India
}

\begin{abstract}
The article is about the selection and ranking of cold chain logistics service provider in pharmaceutical industry. For this study the diabetics drugs (Insulin) were taken for the cold chain, habitually and typically used in supplying insulin over different merchant.The insulin has to be kept, to be maintained and stored then given to merchants for the usage of customer requirement.The major objective of this paper is to select and rank alternative logistics service provider for the manufacturer, since there were many logistics service provider in India.This proper channels has to be properly done and maintained by the third party logistics provider, where from the multi criteria decision making purpose AHP and FAHP technique are to be used for selecting the best service provider.
\end{abstract}

\section{KEY WORDS}

Cold chain, pharmaceutical industry, ranking, AHP and FAHP technique.

\section{INTRODUCTION}

The third party logistics provider had widely extended their service for the customer satisfaction in the market. The emerging and fast growing in logistic service provider is cold chain, the cold chain logistics (like DHL, TVS logistic services) refers to the transportation of temperature sensitive material along with the supply chain, relies on the thermal and refrigerated packaging methods and logistics planning to protect the value of a shipment.

[1] The cold chain is generally considered as the transport and storage chain between the initial production and the final consumer of temperature-controlled perishable goods. This is not a complete definition, as there are other items carried under temperature control, for example works of art. For the purposes of this paper, only the transport and storage of perishable foodstuffs and pharmaceuticals will be considered.

Whereas those incentives are 100\% FDI (Foreign Direct Investment) is allowed through automatic route, then since from 2011-2012, cold chain has been given the infrastructure status, viability gap funding up to $40 \%$ of the cost, the monetary and tax benefits of $5 \%$ concession on 
import duty, service tax exemption, excise duty exemption on several items. The subsidy of over $25 \%$ to $33 \%$ on the cold storage project cost these are been provided by the government.

The Indian cold chain market is highly fragments with more than 3,500 companies in the whole value system. The organized players contribute only $8 \%-10 \%$ of cold chain industry market. Were AHP and TOPSIS methods can be used for the selection these process can be applied. This is an appropriate method.

\section{THIRD PARTY LOGISTICS:}

The term "Third party logistics (3PL)" [7] describes to the organizational practices of contracting-out part of all logistics activities that performed in-house. 3PL is always linked with the offering of bundled services rather than only transport or warehousing functions.

[8] Conclude that the most common reason of outsourcing are: cost reduction, improvement of service level and increase in operational flexibility. Term as "Logistics service Providers (LSP's)" has been used interchangeably and [9] defined LSPs as companies provide logistics services on behalf of other industrial sectors.

The classification of three major groups of 3PL by [9]also reflects the development of 3PL companies' logistics functions: the first group only has standardized and isolated logistics services, such as transportation and warehousing; the second group not only has standardized services, but also has other undifferentiated logistics services for all potential customers according to their customers' wishes; the third group design logistics services and logistics systems according to specific customers' preferences.

Various logistics activities associated with five major functions of 3PL: transportation, warehousing, inventory management, order processing and information system, and packaging [9] .In this para delfmann quoted that the third party logistics are having five major functions in the logistics activity were as this paper focus only on the logistics activity in which they are to select the best logistics service provider in pharmaceutical industry.

\subsection{COLD CHAIN LOGISTICS:}

[10]Argue that the both supply chain and cold chain management could be defined under the "umbrella" of the sustainable production and consumption.[11] The cold chain refers to a physical process that dominates the supply chain logistics of certain processed food. Equipment and facilities are used in the cold chain to protect the chilled and frozen drugs.

[12] Another definition to the cold chain: "a cold chain is a supply chain of perishable items". Furthermore a cold chain can be used in many other areas, such as food, pharmaceutical and chemical products. The common thing of those products is the high requirements on the temperature, humidity, light or other particular conditions.

The two main differences between supply chain and the cold chain are: first, compared with supply chain, the cold chain demands a lot on the operating conditions; second, from the production spots to the consuming place, product in the cold chain have the possibility to spoil [13]. Meanwhile the relationship between supply chain and cold chain can be viewed as facilities 
and conditions demanded in a supply chain [11] and sustainability is important for both of them [10]

\subsubsection{COMPOSITION OF THE COLD CHAIN LOGISTICS:}

Cold chain service of Third party logistics (3PL) companies can be classified into three processes Cold Processing, cold Storage and cold transportation. Were these are said to be composition of the cold chain are given and explained below:

\section{- COLD PROCESSING:}

[14] Define this process, as primary chilling and secondary cooling. The temperature of this stage is vital factor of safety and quality. Cutting and quick frozen machineries are the needed in this stage and a low temperature workshop is also needed.

\section{- COLD STORAGE:}

[15] Cold storage is defined by a process that storing perishable pharmaceuticals, foods or the other items under refrigeration. It is obvious that refrigerator is needed. While during the storage process, the monitor of the product quality should be paid special attention.

\section{- COLD TRANSPORTATION AND DISTRIBUTION:}

[16] Describes cold chain logistics process as sorting, distributing and transporting various cold, chilled, frozen and fresh products to individual or enterprise consumers, in addition, the customer types are food manufacturer and channel dealer, and the transportation type is refrigerated transportation.

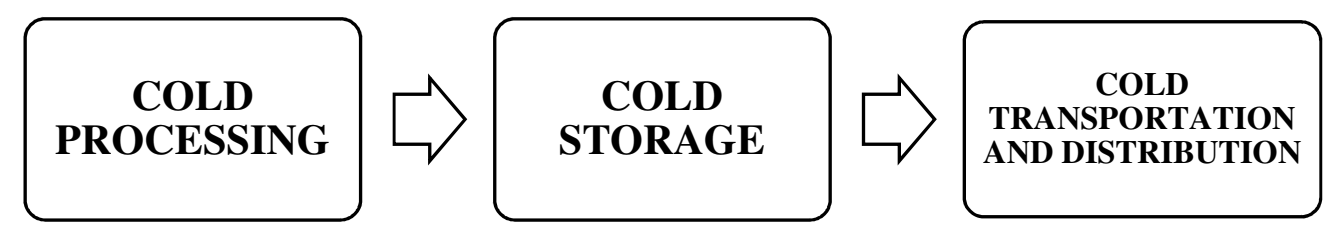

Figure 1. Process of cold chain logistics

\section{DATA ANALYSIS:}

Qualitative method is improved in this study. Qualitative method is used to view the nature of the facts and to support the analysis of the phenomenon. It involves the interpretation of a variety of empirical studies, such as case study, personal experience, face to face interview, life story and historical texts[17]

The empirical information was collected by the interview with the manager of pharmaceutical merchant. By using the factors the questioner were prepared for the effectiveness of service 
provided in cold chain logistics. These factors are gathered from the direct survey from the retailers those who adopt the cold chain logistics for the insulins.

Time delivery: In Pharmaceutical industry, the delivery of drugs according to the demand for the drug and urgency of the drug for the customer's.

Support service: The support service plays a vital role in the service providers were the up to date information of drug has to be given to the both customer and manufacture.

Responsiveness: Its deals with the maintenance of drugs in cold chain. The maintenance includes temperature and packing.

Price: In pharmaceutical industry, the price plays major role because it deals with the storage cost, transportation and manufacturing cost.

Flexibility:the flexibility in the cold chain is the comfortless of both the manufacturer and merchant because they had to maintain the good relationship with the merchant and manufacturer.

Reputation \& Quality: reputation is one of the major concern because the pharmaceutical industry, drug manufacturer had to have relationship with many years. The stockist usually purchase drugs or other medicines with reputed manufacturer.

Technology: The technology helps to track the service provider using RFID tracker, by using the ERP software it is easy to procure, order and place the insulin for the requirement.

When it comes to quality the insulin that has to be more efficient for the customer when its quality comes it will get perishable and cant used.

[18] Brings out the idea of "distribution initiative". It means that companies should take the initiative to develop the distribution network in an establish supply chain. In the pharmaceutical industry, these insulin are been cold chain service providers.

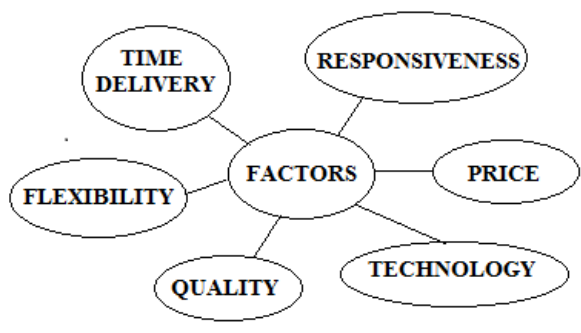

Figure.2 Factors for selecting a cold chain service provider

\subsection{COLD CHAIN IN PHARMACEUTICAL INDUSTRY:}

Cold chain in the pharmaceutical industry is an important, according to[19] in pharmaceutical industries, the cold chain plays a major role. Where the supply of drugs or medicine with precise quantity and quality to be delivered to accurate place and customers and at correct time. Why because the insulin's are the fast moving product according to pharmaceutical industry. if they didn't delivery it on accurate time it may lead to failure for the customer.

[20]Probably the single most important driver in the pharmaceutical industry is the time-tomarket. Companies secure very significant returns in the early life of a successful drug before any competition. 


\subsection{Components:}

In pharmaceutical industry players are,

1) Primary manufacturing,

2) Market warehouse/ distribution centres,

3) Merchant and

4) Retailers/ hospitals.

\subsection{Flow Of Distribution:}

The flow of distribution in cold chain of insulin is like straight distribution flow of cold chain. While considering the pharmaceutical industry the manufacturing of drugs/ insulin from single company and received to the different distribution centres and those insulin are sent to single retailer. This flow of distribution in the cold chain is show in the figure. 3 whereas this flow of distribution is gathered from the local retailers and manufacturer.

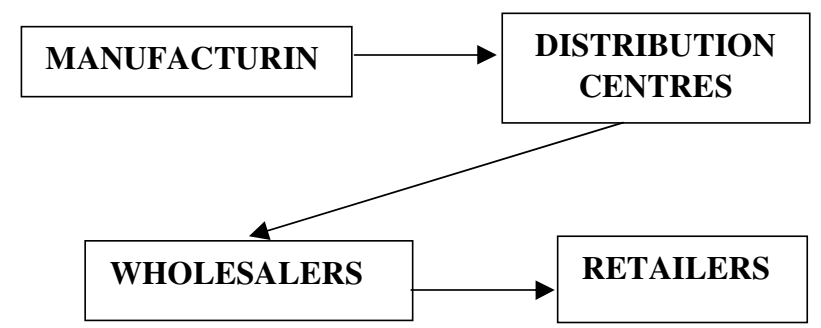

Figure.3Flow of single drug distribution

While in case of multiple volume of products, which will be having multiple manufacturing of single product is received by multiple distribution flow. As shown in figure below manufacturer share the logistics service provider and deliver their product to same distribution centre then finally to one retailer. This is been shown in the figure. 4

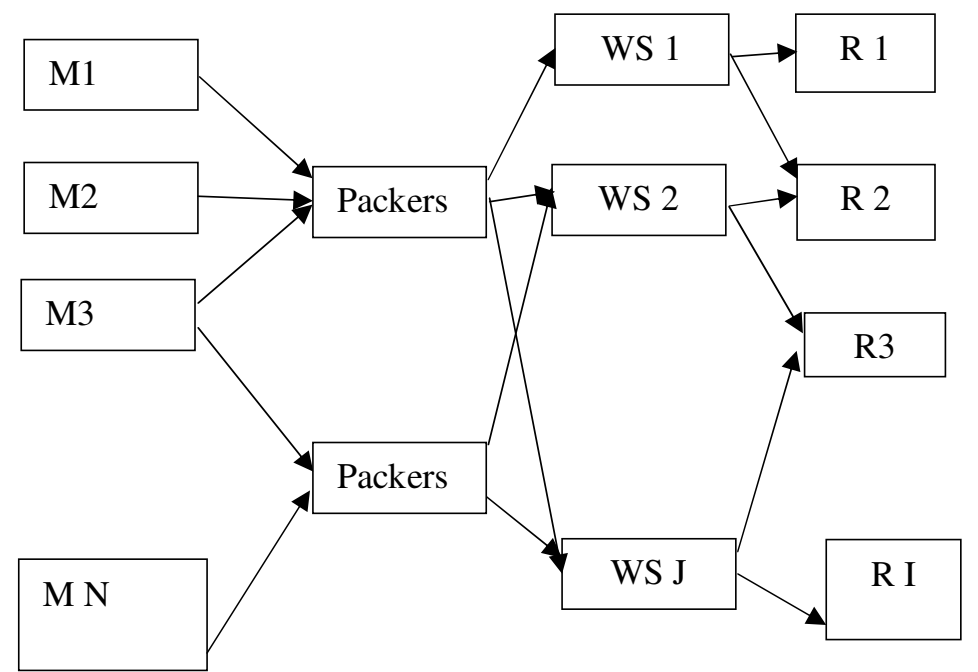

Figure.4 Flow of single drug from multiple distribution 


\section{Research Methodology \\ 4.1 Research design:}

The research design used for this study is descriptive research, where facts and findings are done and the census survey is aided for the next step of this research.

\subsection{Data collection and Questioner design:}

The data collection is done by both primary and secondary data collection, were primary data collection is done by direct interview and through questioners from the retailers and secondary data collection gathered from the official website from the pharmacy.

The questioner designed by using rating scale, in rating scale the numeric rating scale is used and a scale used for the subjective measurement of a clinical sign/syndrome, in which numerical scores are given (e.g. 0-9). A description is given for each score. In the questioners closed and opened questioners are been used.

The tools used for this study is Analytical hierarchy process (AHP) and Fuzzy analytical hierarchy process (FAHP).these are the tools which are used for the multi criteria decision making and stages are explained with the derivation. (Nadia Jamil, RosliBesar, H.K.Sim, 2013) these steps are been taken and followed.

Analytical hierarchy process (AHP) introduced by Thomas Saaty (1980), is an effective tool for dealing with complex decision making, and may aid the decision maker to set priorities and make the best decision.

1) Computing the vector of criteria weights.

2) Computing the matrix of option scores.

3) Ranking the options.

Each step will be described in detail in the following.

It is defined as variables with values expressed by words in a natural language. There are three principles used in solving problems with AHP in supplier selection which are as follows.

(i) AHP establishes the priorities based on sets of pairwise comparisons.

(ii) AHP score is built on human attributes and judgements where the intensity of each attribute or judgment is set according to its hierarchy over the other.

(iii) AHP synthesizes these judgments by using the hierarchy framework to obtain the overall priority of the elements or factors.

Triangular Fuzzy Number (TFN). There are 2 types of TFN which are symmetry and unsymmetry.

TFN can be defined in three numbers, $(l, m, u)$ which represented the smallest possible value, the most promising value, and the largest value which describes the fuzzy event. 
This representation can be observed from Figure 5 which illustrates symmetry TFN. Throughout this study, the commonly used algebraic operations for fuzzy numbers are addition and multiplication. The fuzzy operators shown below were adapted from.

\begin{tabular}{|c|c|c|}
\hline Linguistic Scale & rating scale & TFN \\
\hline Just equal & 1 & $(1,1,1)$ \\
\hline morderately important & 3 & $(2,3,4)$ \\
\hline strongly important & 5 & $(4,5,6)$ \\
\hline very strongly importan & 7 & $(6,7,8)$ \\
\hline extremely important & 9 & $(9,9,9)$ \\
\hline intermediate values & $2,4,6,8$ & $(7,8,9),(5,6,7),(6,4,5),(1,2,3)$ \\
\hline
\end{tabular}

Figure 5. Triangular fuzzy number for this study

Fuzzy analytical hierarchy process (FAHP) There are 6 steps in the process of decision making using FAHP. These steps are as follows.

(1) Firstly, form a decision matrix (pair wise comparison matrix).

(2) The membership function of triangular fuzzy number is defined by three real numbers $(l, m$, $u$ ) which is mathematically described as $[\mu A(x)]$. The comparison matrix is derived from equation 1. Equation 1 is as follow

$$
\begin{gathered}
\mu_{A}(x)= \begin{cases}\frac{(x-l)}{m-l}, & l \leq x \leq m \\
\frac{u-x}{u-m}, & m \leq x \leq u \\
0, & \text { otherwise, }\end{cases} \\
a_{i j}=\frac{1}{a_{i j}}\left\{\begin{array}{c}
a_{i j}=\left(l_{i j}, m_{i j}, u_{i j}\right) \\
a_{i j}=\left(\frac{1}{u_{i j}}, \frac{1}{m_{i j}}, \frac{1}{l_{i j}}\right) .
\end{array}\right.
\end{gathered}
$$

(3) Calculate the Gi (objective) which is defined by Chang in 1992 in his study of fuzzy extent analysis. The computations of $G i$ are explained in equation (2) as follows

$$
\begin{gathered}
\widehat{G}_{i}=\left(l_{i}, m_{i}, u_{i}\right), \\
l_{i}=\left(l_{i 1} \otimes l_{i 2} \otimes \cdots \otimes l_{i k}\right)^{1 / k} \quad i=1,2, \ldots, k, \\
m_{i}=\left(m_{i 1} \otimes m_{i 2} \otimes \cdots \otimes m_{i k}\right)^{1 / k} \quad i=1,2, \ldots, k, \\
u_{i}=\left(u_{i 1} \otimes u_{i 2} \otimes \cdots \otimes u_{i k}\right)^{1 / k} \quad i=1,2, \ldots, k .
\end{gathered}
$$

(4) The next step is the calculation of GT (total objective) where by the equation used is displayed in equation(3) as 


$$
\widehat{G}_{T}=\left(\sum_{i=1}^{k} l_{i}, \sum_{i=1}^{k} m_{i}, \sum_{i=1}^{k} u_{i}\right) .
$$

(5) Weight of each criterion with respect to the objective is calculated. The equations used are shown in equation(4) as

$$
\begin{aligned}
\widehat{w} & =\frac{\widehat{G}_{i}}{\widehat{G}_{T}}=\frac{\left(l_{i}, m_{i}, u_{i}\right)}{\left(\sum_{i=1}^{k} l_{i}, \sum_{i=1}^{k} m_{i}, \sum_{i=1}^{k} u_{i}\right)} \\
& =\left[\frac{l_{i}}{\sum_{i=1}^{k} u_{i}}, \frac{m_{i}}{\sum_{i=1}^{k} m_{i}}, \frac{u_{i}}{\sum_{i=1}^{k} l_{i}}\right] .
\end{aligned}
$$

(6) The final stage is defuzzification whereby triangular fuzzy numbers are transformed into real numbers which is defined as weights (Win) and can be computed in equation(5) as

$$
W_{i n}=\frac{w_{i d}}{\sum_{i=1}^{k} w_{i d}}, \quad i=1,2, \ldots k .
$$

\subsection{RESULTS AND DISCUSSIONS}

\subsubsection{Fuzzy Analytical hierarchy Process (FAHP)}

Step 1: To create a pairwise comparison matrix using data collection

The pairwise matrix is created by using data collection where from the data collection, the mean and average are to calculate from the respondent which is expressed in table. 1.

Table 1. Weighted mean percentage

\begin{tabular}{|c|c|c|c|c|c|c|c|}
\hline & \multicolumn{5}{|c|}{ WEIGHTED MEAN (\%) } & & \\
\hline & V1 & V2 & V3 & V4 & V5 & V6 \\
\hline DTDC & 104.4 & 84.43 & 102.2 & 115.5 & 102.2 & 95.5 \\
\hline ST.COURIER & 93.3 & 91.11 & 93.33 & 97.78 & 84.4 & 97.78 \\
\hline ABT PS & 71.1 & 62.22 & 66.67 & 82.2 & 82.2 & 88.89 \\
\hline HFC LOGISTICS & 111.1 & 108.89 & 120 & 144.4 & 144.4 & 120 \\
\hline VRL & 86.67 & 75.56 & 104.4 & 97.78 & 88.89 & 77.78 \\
\hline KPN & 66.67 & 55.56 & 75.76 & 73.33 & 82.22 & 66.6 \\
\hline
\end{tabular}

Then the pairwise comparison matrix is created on the basis of the ranking or ordering on the basis of weight, shown in table 2. 
International Journal of Managing Value and Supply Chains (IJMVSC) Vol. 8, No. 2, June 2017

Table.2 Pairwise comparison matrix for AHP

\begin{tabular}{|c|c|c|c|c|c|c|}
\hline & \multicolumn{4}{|c|}{ PAIRWISE COMPARISON MATRIX } & & \multirow[b]{2}{*}{ KPNPS } \\
\hline & DTDC & COLDEX & ABT PS & HFC LOGISTICS & VRL & \\
\hline DTDC & 1 & 3 & 5 & 2 & 4 & 6 \\
\hline COLDEX & $(1 / 3)$ & 1 & 6 & 2 & 4 & 5 \\
\hline ABT PS & $(1 / 5)$ & $(1 / 6)$ & 1 & 2 & 3 & 6 \\
\hline HFC LOGISTICS & $(1 / 2)$ & $(1 / 2)$ & $(1 / 2)$ & 1 & 3 & 5 \\
\hline VRL & $(1 / 4)$ & $(1 / 4)$ & $(1 / 3)$ & $(1 / 3)$ & 1 & 4 \\
\hline KPNPS & $(1 / 6)$ & $(1 / 5)$ & $(1 / 6)$ & $(1 / 5)$ & $(1 / 4)$ & 1 \\
\hline & & & & & & \\
\hline SUM & 2.45 & 5.12 & 13 & 7.53 & 15.25 & 27 \\
\hline
\end{tabular}

After the pairwise comparison matrix, next step is to find matrix of option score for that the normalized pairwise comparison matrix are formed and average are to be explained in the Table 3.

Table. 3Normalized pairwise comparison matrix

\begin{tabular}{|c|c|c|c|c|c|c|}
\hline & \multicolumn{5}{|c|}{ NORMALIZED PAIRIISE COMPARISON MATRIX } \\
\hline & DTDC & ST.COLRIER & ABT PS & HFC LOGISTICS & VRL & KPNPS \\
\hline DTDC & 0.4082 & 0.5859 & 0.3846 & 0.2656 & 0.2623 & 0.222 \\
\hline ST.COURIER & 0.1361 & 0.1953 & 0.4615 & 0.2656 & 0.2623 & 0.1852 \\
\hline ABT PS & 0.0816 & 0.0326 & 0.0769 & 0.2656 & 0.1967 & 0.222 \\
\hline HFC LOGISTICS & 0.2041 & 0.0977 & 0.0385 & 0.1328 & 0.1967 & 0.1852 \\
\hline VRL & 0.102 & 0.0488 & 0.0256 & 0.0443 & 0.0656 & 0.1451 \\
\hline KPN & 0.068 & 0.0391 & 0.0128 & 0.0266 & 0.0164 & 0.037 \\
\hline & & & & & & \\
\hline
\end{tabular}

Step 2: From the normalized decision matrix the average is calculated and from the calculated averages the priority based is consider \& it shown in table. 4

Table .4 Priority basis using AHP

\begin{tabular}{|c|c|}
\hline \multicolumn{2}{|c|}{ PRIORITY BASIS USING AHP } \\
\hline & \\
\hline DTDC & 0.3548 \\
\hline ST.COURIER & 0.251 \\
\hline ABT PS & 0.1459 \\
\hline HFC LOGISTICS & 0.1425 \\
\hline VRL & 0.0724 \\
\hline KPN & 0.0333 \\
\hline
\end{tabular}


Step 3:Ranking the options using the AHP method

1. $\quad$ DTDC with weighted value 0.3548 .

2. COLDEX with weighted value 0.251.

3. $\quad$ ABT PS with weighted value 0.1459 .

4. HFC logistics with weighted value 0.1425 .

5. $\quad$ VRL with weighted value 0.0724 .

6. KPN PS with weighted logistics value 0.0333 .

The consistency ratio has to find at this stage, the consistency ratio is to find how effective the AHP process is, if the ratio is less than 0.1 then we can proceed with this method if the ratio is greater than 0.1 then the assumption of the weighted means are to be change and to repeat from the step 1 .The consistency ratio equation is

$$
\begin{aligned}
& \text { Consistency ratio }[\mathrm{CR}]=\mathrm{CI} / \mathrm{RI} \\
& {[\mathrm{CR}]=0.0574}
\end{aligned}
$$

As the consistency ratio is less than $0.1[<0.1]$ the next step can be proceed. The next step is to proceed with the fuzzy analytical hierarchy process (FAHP).

\subsubsection{Fuzzy Analytical hierarchy Process (FAHP)}

The Fuzzy analytical hierarchy process step are followed below.

Step 1: To create a pairwise comparison matrix using data collection

Step 2: From the normalized decision matrix the average is calculated and from the calculated averages the priority based is consider.

Step $1 \&$ step 2 are repetitive in this FAHP, later from the step 2. Next is to find step 3.

Step 3: Form a decision matrix (i.e pairwise comparison matrix). This matrix is formed by using the triangular fuzzy number (TFN) which applied in the Step 1 of AHP.

\begin{tabular}{|c|c|c|c|c|c|c|}
\hline & \multicolumn{5}{|c|}{ 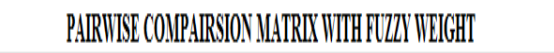 } & \\
\hline & DTDC & COLDEX & $A B T P S$ & Heclogistics & IRL & IPYPS \\
\hline$D T D C$ & (1.1.1.) & (23,4) & $(4,6,6)$ & $(78,9)$ & $(3,6,7)$ & $(3,4,5)$ \\
\hline COLDES & $(12,1,1,14)$ & $(1,1,1,1)$ & $(3,4,5)$ & $(7,89)$ & $(5,6,7)$ & $(4,5,0)$ \\
\hline ABTPS & $(1,1,1,15,16)$ & $(113,1,1,1,15)$ & $(1,1.11)$ & $(7,89)$ & $(2.44)$ & $(3,5,5)$ \\
\hline Heclocistics & $(17,18,19)$ & $(17,18,19)$ & $(17,18,19)$ & $(1,1,1)$ & $(2,34)$ & $(4,5,0)$ \\
\hline IRL & $(15,16,17)$ & $(15,16,17)$ & $(110,13,14)$ & $(11,113,14)$ & $(1,1,1)$ & $(56,7)$ \\
\hline KRYPS & $(13,14,15)$ & $(14,1 / 1), 16)$ & $\left.(18,1,1,1: 1)^{2}\right)$ & $(14,15,16)$ & $(1.1 .16,117)$ & $(1,1,1)$ \\
\hline
\end{tabular}

Table 5. Pairwise comparison matrix with Fuzzy weight.

Step 4: The above matrix is formed using the table 5. TFN numbers that are assigned using the equation 2 . Were figure 5 is been used 
International Journal of Managing Value and Supply Chains (IJMVSC) Vol. 8, No. 2, June 2017

Step 5:Upon getting the result for GT, weight of each criterion with respect to the objective is calculated.

Table 6. Normalized weighted mean for Fuzzy AHP

\begin{tabular}{|c|c|c|c|c|c|c|}
\hline & & \multicolumn{3}{|c|}{ NORVIALIZED NEIGHIED MEAN FOR FUZZY AHP } & & \\
\hline $\mathbb{W i}_{\mathrm{i}}$ & DIDC & SI.COLRIER & ABTPS & HFC LOGISTICS & VRLLOGISTICS & KPNPS \\
\hline DIDC & $(2.475,2.890,3,2.205)$ & $(3,058,3,797,4,4,111)$ & $(2,674,2.734,2,2865)$ & $(1.846,1.880,1,900)$ & $(1.974,1,785,1,1478)$ & $(0,900,0,960,1,000)$ \\
\hline SI.COLRIER & $(1.238,0,963,0,0.801)$ & $(1.529,1,1.266,1,028)$ & $(2.005,2,1.187,2,2388)$ & $(1.846,1.880,1.900)$ & $(1.974,1.785,1,1778)$ & $(1,200,1,200,1,1200)$ \\
\hline ABTPS & $(0.825,0,5758,0,5344)$ & $(0,510,0,316,0,0.206)$ & $(0.668,0,547,0.0478)$ & $(1.846,1.880,1,900)$ & $(0.790,0.893,0,04845)$ & $(0,900,0,960,1,000)$ \\
\hline HFC LOGISTICS & $(0.354,0,361,0,356)$ & $(0.218,0,158,0,0.114)$ & $(0.095,0.068,0.0533)$ & $(0.264,0.235,0.211)$ & $(0,790,0,893,0,845)$ & $(1,200,1,200,1,200)$ \\
\hline VRLLOGISTICS & $(0.495 ; 0,482,0,458)$ & $(0,306,0,211,0,147)$ & $(0.334,0,0182,0.119)$ & $(0.182,0.078,0,0.033)$ & $(0,395,0,298,0,211)$ & $(1,500,1,440,1,400)$ \\
\hline KPNPS & $(0,825,0,723,0,641)$ & $(0.382,0.253,0,171)$ & $(0.223,0,137,0,090)$ & $(0.053,0,047,0.035)$ & $(0.079,0,0.050,0,0.030)$ & $(0,300,1,200,0,200)$ \\
\hline
\end{tabular}

From this normalized weighted mean for FAHP, the average is been calculated and ranked in the order of priority basis.

Step 6: the final fuzzy AHP is derived with the process of ranking in the order

- $\quad$ First weight for criteria - DTDC (1.960)

- $\quad$ Second weight for criteria- COLDEX (1.871)

- $\quad$ Third weight for criteria- ABT PS (0.8230)

- $\quad$ Fourth weight for criteria- HFC LOGISTICS (0.8120)

- $\quad$ Fifth weight for criteria- VRL (0.7741)

- Sixth weight for criteria- KPN PS (0.6890)

\section{CONCLUSION}

The selection of cold chain service provider in pharmaceutical industries had be studied and AHP \& FAHP are calculated besides the DTDC, COLDEX,ABT PS, HFC LOGISTICS, VRL, KPN PS are the service providers are ranked and selected for future. From this techniques, service providers are ranked on the basis of their weighted \& criteria it's clearly (i.e the DTDC is ranked as first and this is selected cold chain logistics service provider in pharmaceutical industry[15]). These ranked service providers are best in the six criteria which merchant are used to select the service provider. This multi criteria decision making process will reduce the time and easy to choose the leading service provider in the field of pharmaceutical industry. Further the selection of multi criteria can done in other technique like FTOPSIS and TOPSIS.

\section{ACKNOWLEDGEMENTS}

The authors would like to thank Associate ProfessorDr. Saravanan.Sfor the guidance for this project, all the survey respondents for their kind support and help contributed towards the 
implementation of this paper. Special thanks go to all retailer and manufacturer those who provided data on for the study.

\section{REFERENCES}

[1] R. D. HEAP, "COLD CHAIN PERFORMANCE ISSUES NOW AND IN THE FUTURE," Innovative equipment and systems for comfort \& food preservation, 2006.

[2] S. B. Ravindra Kumar, "COLD CHAIN FOR VACCINE," Journal of Drug Delivery \& Therapeutics, pp. 46-50, 2012.

[3] X. L. W. C. Jiuyi An, "A Review of Literature for Research on Urban Demand Oriented AgriFood Cold Chain Logistics Management System," Open Journal of Social Sciences, pp. 111-120, 2013.

[4] Kausar Shafaat, "AN OVERVIEW: STORAGE OF PHARMACEUTICAL PRODUCT," world journal of pharmacy and pharmaceutical sciences, pp. 2499-2515, 2013.

[5] S. W. Yogini Thakker, "Storage ofvaccines in the community: weak link in the cold chain?," BMJ, pp. 756-759, 1992.

[6] V. Rattanawiboonsom, "Effective Criteria for Selecting Third-Party logistics Providers: The Case of Thai Automotive Industry," World Review of Business Research, p. 196 - 205 , 2014.

[7] R. \&. J. R. Wilding, "Customer perceptions on logistics outsourcing in the European consumer goods industry," International Journal of Physical Distribution \& Logistics Management, pp. Vol. 34 No. 8, pp. 628-644, 2004.

[8] W. A. S. \&. G. M. Delfmann, "The impact of electronic commerce on logistics service providers," International Journal of Physical Distribution \& Logistics Management, pp. Vol. 32 No. 3, pp. 203-222., 2002.

[9] S. W. a. V. R. Maxwell D., "Functional and systems aspects of the sustainable product and service development approach for industry," Journal of cleaner production, pp. 399-413, 2006.

[10] a. N. R. Salin V., "a cold chain network for food exports to developing countries," International Journal of Physical Distribution \& Logistics Management, pp. 918-933, 2002.

[11] R. bishara, "cold chain managemnt- essential component of the global pharmaceutical supply chain," january/februray $2006 . \quad$ [Online]. Available: http://portugues.sensitech.com/assets/articles/lsbisharaapr.pdf.

[12] B. D. a. s. R. joshi R, "indian cold chain : modelling the inhibitors,," british food journal, pp. 1260-1283, 2009.

[13] S. \&. J. James, "The Food cold-chain and climate change," Food Research International , pp. Vol.43 No.7, PP 1944-1956, 2010.

[14] S. Akdemir, "“Designing of cold stores and choosing of cooling system elements," Journal of Applied Science, pp. 788-794, 2008.

[15] J. \&. C. M. Kuo, "Developing an advanced multi-temperature joint distribution system for the food cold chain," Food Control, pp. Vol. 21 No. 4, pp.559-566, 2010.

[16] a. U. J. Neergaard H., Handbook of Qualitative Research Methods in Entrepreneurship, Edward Elgar Publishing Limited.

[17] A. A. Wagner B.A, "managing the distribution channel: the case of scot trout and salmon," supply chain management: an international journal, pp. 104-107, 2006.

[18] S. N. a. a. a. R. d. Mona jaberisdoost, "Pharamaceutical supply chain risks: a systematic review," DARU Journal of Pharmaceutical Sciences, 2013.

[19] N. shah, "Phaemaceutical supply chains: key issues and straregies for optimisation," computers and chemical engineering, pp. 929-941, 2004.

[20] M. D, s. W and v. R. V.D, "Functional and system aspects of the sustainable product and service development approach for industry," journal of cleaner production, pp. 399-416, 2006.

[21] S.saravanan and anubama.b, "A STUDY ONCOLD CHAIN LOGISTICS SERVICE PROVIDER IN PHARMACEUTICAL INDUSTRY ", International Journal of Universal Pharmacy and Bio Sciences 6(2): March-April 2017, pp.31-40. 